\title{
IKK $\alpha$ is required in the intestinal epithelial cells for tumour stemness
}

\author{
Carlota Colomer ${ }^{1}$, Pol Margalef ${ }^{1,2}$, Jessica Gonzalez ${ }^{1}$, Anna Vert ${ }^{1}$, Anna Bigas ${ }^{1}$ and Lluis Espinosa ${ }^{*}, 1$ \\ ${ }^{1}$ Cancer Research Program, Institut Mar d'Investigacions Mèdiques, CIBERONC, Hospital del Mar, Doctor Aiguader 88, 08003 \\ Barcelona, Spain and ${ }^{2}$ DSB Repair Metabolism Laboratory, The Francis Crick Institute, London NW1 1AT, UK
}

Background: Colorectal cancer is a common cause of death in developed countries. Progression from adenoma to invasive carcinoma requires accumulation of mutations starting with the Adenomatous Polyposis Coli (Apc) gene. NF- $\kappa$ B signalling is a key element in cancer, mainly related to the activity of IKK $\beta$. IKK $\alpha$ kinase also participates in this process by mechanisms that are primarily unknown.

Methods: We generated a compound mouse model with mutation in Apc and lacking intestinal epithelial IKK $\alpha$, produced intestinal organoids and tumour spheroids with different genetic backgrounds, and performed immunohistochemistry and RNAseq analysis.

Results: Deficiency of IKK $\alpha$ prevents adenoma formation, with adenomas lacking IKK $\alpha$ showing reduced proliferation. In contrast, IKK $\alpha$ status did not affect normal intestinal function. The same divergent phenotype was found in the organoid-spheroid model. We also found that epithelial IKK $\alpha$ controls stemness, proliferation and apoptosis-related expression.

Conclusions: IKK $\alpha$ is a potential therapeutic target for Apc mutant colorectal cancer patients.

Colorectal cancer (CRC) is the second leading cause of cancerrelated death in Western populations. Indeed, around half of the population will develop at least one benign tumour during their lifetime (Jemal et al, 2011).

Several studies revealed a series of molecular events that are critical for the progression from colon adenoma to invasive carcinoma (Fearon and Vogelstein, 1990; Fearon, 2011). One of the earliest events is the inactivating mutation in the Adenomatous Polyposis Coli $(A P C)$ tumour suppressor gene that leads to the activation of the Wnt signalling pathway, a key regulator of intestinal stemness. In fact, $A p c$ loss is sufficient to induce multiple adenomas in the mouse intestine ( $\mathrm{Su}$ et al, 1992; Cheung et al, 2010; Dow et al, 2015). The Apc $c^{\mathrm{Min} /+}$ (multiple intestinal neoplasia) mouse model carries a single $A p c$ mutation that is sufficient to induce the development of hundreds of benign adenomas in the small intestine of the mice by 4 to 6 months of age. Besides APC, mutations in KRAS, p53 and the transforming growth factor $\beta$ (TGF $\beta$ ) pathways are known to be crucial for CRC progression (Fearon and Vogelstein, 1990; Drost et al, 2015).
The current treatments for advanced CRC include surgery, and a combination of chemotherapies that are ineffective in a proportion of cases. Hence, it is of crucial importance to identify new therapeutic targets that can be exploited to improve CRC treatment and patient survival.

The nuclear factor- $\kappa \mathrm{B}(\mathrm{NF}-\kappa \mathrm{B})$ is a key transcription factor that not only mediates innate and acquired immune responses but also regulates inflammation and carcinogenesis (Hayden and Ghosh, 2004; Hayden et al, 2006; Schulze-Luehrmann and Ghosh, 2006). Activation of the pathway by different stimuli such as tumour necrosis factor- $\alpha(\mathrm{TNF} \alpha)$, bacterial and viral products or DNA damage induces the phosphorylation of the inhibitor of $\mathrm{NF}-\kappa \mathrm{B}(\mathrm{I} \kappa \mathrm{B})$ kinase (IKK) complex downstream of transforming growth factor $\beta$-activated kinase 1 (TAK1). This complex is composed by $\operatorname{IKK} \alpha, \quad \operatorname{IKK} \beta$ and $\operatorname{IKK} \gamma / \mathrm{NF}-\kappa \mathrm{B}$ essential modulator (NEMO) (Ghosh and Karin, 2002) that phosphorylates $\mathrm{I} \kappa \mathrm{B}$ leading to its ubiquitination and subsequent degradation. Degradation of $\mathrm{I} \kappa \mathrm{B}$ allows the nuclear translocation of the $\mathrm{NF}-\kappa \mathrm{B}$ factor, mostly $\mathrm{p} 65 / \mathrm{p} 50$ dimers, leading to the activation

*Correspondence: Dr L Espinosa; E-mail: lespinosa@imim.es 
of the canonical pathway. The IKK $\alpha$ subunit also participates in the activation of the alternative NF- $\kappa \mathrm{B}$ pathway that is independent of IKK $\beta$, NEMO and TAK1 (Vallabhapurapu and Karin, 2009). Specifically, factors inducing alternative NF- $\kappa \mathrm{B}$ lead to the stabilisation of the NF- $\kappa \mathrm{B}$-inducing kinase (NIK) that in turn activates IKK $\alpha$ to phosphorylate p100. This cascade results in the proteolytic processing of p100 into p52 that will then translocate into the nucleus together with RelB to activate specific gene transcription.

Mostly related with its role in inflammation, several studies have demonstrated the association between NF- $\kappa \mathrm{B}, \mathrm{IKK} \beta$ and cancer (Karin and Greten, 2005). In parallel, other reports identified NF$\kappa \mathrm{B}$-independent functions that are carried out by elements of the pathway, thus contributing to specific tumourigenic capabilities. Some examples are found in squamous cell carcinoma (SCC), where IKK $\alpha$ induces the release of SUMO-I $\kappa \mathrm{B} \alpha$ from the chromatin leading to $\mathrm{HOX}$ and IRX gene transcription (Mulero et al, 2013). Also in SCC, nuclear IKK $\alpha$ regulates the levels of the metastasis suppressor gene Maspin (Toll et al, 2015), similar to that found in prostate cancer cells (Luo et al, 2007). In CRC, nuclear IKK $\alpha$ regulates the transcription of Notch target genes by phosphorylating the silencing mediator for retinoid and thyroid receptors (SMRT) and the nuclear receptor corepressor (N-CoR) (Fernández-Majada et al, 2007a, b). Moreover, the presence of nuclear active IKK $\alpha$ correlates with cancer progression, and we recently identified a novel IKK $\alpha$ isoform with a predicted molecular weight of $45 \mathrm{kDa}(\mathrm{p} 45-\mathrm{IKK} \alpha)$ that lacks several regulatory regions at the $\mathrm{C}$-terminal end of the kinase (Margalef et al, 2012). Active p45-IKK $\alpha$ localises in the nucleus of CRC cells and forms a complex with non-phosphorylated full-length IKK $\alpha$ and NEMO. Activation of this isoform involves the endosomal compartment and is induced by mutant $\mathrm{BRAF}^{\mathrm{V} 600 \mathrm{E}}$ through the kinase TAK1 (Margalef et al, 2015). Furthermore, a mouse model deficient in IKK $\alpha$ kinase activity displays reduced Wnt-driven intestinal tumour development associated with an enhanced recruitment of interferon- $\gamma(\mathrm{IFN} \gamma)$ expressing M1-like myeloid cells (Göktuna et al, 2014). These data demonstrate that IKK $\alpha$ is a key regulatory element of tumourigenesis that acts both in an NF- $\kappa \mathrm{B}$-dependent and -independent manner. In the latter, IKK $\alpha$ might directly regulate essential factors that participate in the oncogenic process. However, to date, there are no conclusive data unveiling the contribution of intestinal epithelial IKK $\alpha$ neither in normal intestinal homeostasis nor in the oncogenic transformation of the intestinal stem and progenitor cells.

We have here generated mice with deletion of IKK $\alpha$ in the intestinal epithelial cells that were crossed with a model of intestinal tumourigenesis driven by APC mutation. We found that intestinal epithelial IKK $\alpha$ is essential for tumour formation while dispensable for normal tissue homeostasis, both in in vivo and $3 \mathrm{D}$ in vitro cultures. Moreover, by RNA sequencing of wild-type (WT) and IKK $\alpha$ knockout (KO) tumouroids, we uncovered the molecular basis of IKK $\alpha$ addiction in transformed cells.

\section{MATERIALS AND METHODS}

Animals. For the generation of intestine-specific IKK $\alpha$ KO animals, the previously described $I k k \alpha^{\mathrm{FL}}$ mice (Gareus et al., 2007) were crossed with the Villin-Cre (from Jackson Laboratories, Bar Harbor, ME, USA) line, both in C57BL/6 background. $A p c^{\text {Min/ }}$ ${ }^{+}$mice (from Jackson Laboratories) were from C57BL/6J background. All mice were genotyped by PCR and animals were kept under pathogen-free conditions. All the animal work was conducted according to the guidelines from Generalitat de Catalunya.

Immunohistochemistry. Formalin-fixed Swiss-roll intestinal samples were embedded in paraffin and sectioned at $4 \mu \mathrm{m}$. After dewaxing and rehydration, antigen retrieval was achieved using standard methods depending on the antibodies. Endogenous peroxidase activity was quenched by incubating the sections for 20 min with $1.5 \% \mathrm{H}_{2} \mathrm{O}_{2}$. Primary antibodies Ki67 (Novocastra, Newcastle, UK, MM1), cleaved caspase 3 (Cell Signaling, Danvers, MA, USA, 9661) and $\beta$-catenin (Sigma-Aldrich, St Louis, MO, USA, C2206) were diluted in PBS containing 0.05\% BSA and incubated overnight at $4{ }^{\circ} \mathrm{C}$. Samples were then incubated with specific horseradish peroxidase (HRP)-labelled polymer (EnVision + System, DAKO, Glostrup, Denmark), and staining was developed using $\mathrm{DAB}+$ Substrate (Chromogen System, DAKO).

Intestinal adenoma isolation and tumouroid culture in Matrigel. Intestinal crypts and adenomas used in the 3D cultures were isolated as previously described (Sato et al., 2011). For organoid culture, we collected mouse small intestines, sliced them longitudinally and washed in cold PBS. Villi were removed by carefully scraping the surface, and the remaining tissue was cut into $3-5 \mathrm{~mm}$ sections. Samples were incubated twice in $2 \mathrm{~mm}$ EDTA for $30 \mathrm{~min}$ at $4{ }^{\circ} \mathrm{C}$, filtered through a $100 \mu \mathrm{m}$ pore diameter nylon and centrifuged at $110 \mathrm{~g}$ to obtain the crypt-enriched fraction. For tumouroid cultures, adenomas were isolated manually and incubated in $8 \mathrm{~mm}$ EDTA for $20 \mathrm{~min}$ at $4{ }^{\circ} \mathrm{C}$. The remaining pellet was treated for $20 \mathrm{~min}$ at $37^{\circ} \mathrm{C}$ in agitation with $0.4 \mathrm{mg} \mathrm{ml}^{-1}$ dispase and subsequently with $1.25 \mathrm{mg} \mathrm{ml}^{-1}$ collagenase each. Cell suspension was centrifuged for $5 \mathrm{~min}$ at 1200 r.p.m. and resuspended in $140 \mathrm{~nm}$ ROCK inhibitor (Y-27632, Sigma) before filtration through 100,70 and $40 \mu \mathrm{m}$ pore diameter nylon meshes, consecutively. After that, cells were centrifuged for $5 \mathrm{~min}$ at 1200 r.p.m. and seeded in Matrigel (Corning, Corning, NY, USA) drops.

Approximately $10^{4}$ cells were seeded in $50 \mu \mathrm{l}$ of Matrigel in 24well plates. After polymerisation, $500 \mu \mathrm{l}$ of complete medium ((DMEM/F12, Biological Industries, Kibbutz Beit-Haemek, Israel) with penicillin $\left(100 \mathrm{U} \mathrm{ml}^{-1}\right)$ and streptomycin $\left(100 \mu \mathrm{g} \mathrm{ml}^{-1}\right)$ (Biological Industries) supplemented with N2 and B27 (Invitrogen, Carlsbad, CA, USA) containing $140 \mathrm{~nm}$ ROCK inhibitor (Y27632, Sigma), $100 \mathrm{ng} \mathrm{ml}^{-1}$ Noggin (Peprotech, London, UK), $100 \mathrm{ng} \mathrm{ml}^{-1} \mathrm{R}$-spondin (R\&D Systems Minneapolis, MN, USA), $50 \mathrm{ng} \mathrm{ml}^{-1} \mathrm{EGF}$ (Sigma) and $20 \mathrm{ng} \mathrm{ml}^{-1}$ basic FGF (Peprotech)) was added and cultures maintained at $37^{\circ} \mathrm{C}$ in $5 \% \quad \mathrm{CO}_{2}$. Tumouroid measurement was performed using the standard parameters in Fiji-ImageJ (https://fiji.sc).

Tumouroid immunostaining. Tumouroids were seeded in Matrigel (Corning) onto a cover glass in a 24 -well plate, and maintained in culture for 2 days. For whole-mount immunostaining, tumouroids were fixed with $4 \%$ paraformaldehyde for $20 \mathrm{~min}$, permeabilised with $0.5 \%$ Triton X-100 (Pierce, Waltham, MA, USA) for $10 \mathrm{~min}$ and blocked in $2 \%$ BSA and $0.3 \%$ Triton X-100 for $1 \mathrm{~h}$. Primary antibody (Ki67, Novocastra, MM1) was incubated overnight. After extensive washing, secondary antibody donkeyanti-mouse Alexa Fluor 488 (Molecular Probes, Eugene, OR, USA) was incubated for $2 \mathrm{~h}$ at room temperature. Slides were mounted in ProLong Diamond Antifade with DAPI (Thermofisher, Waltham, MA, USA).

Western blot analysis. Organoids and tumour spheroids were collected, centrifuged at $600 \mathrm{~g}$ for $5 \mathrm{~min}$ and lysed for $10 \mathrm{~min}$ at $4{ }^{\circ} \mathrm{C}$ in $100 \mu \mathrm{l}$ of RIPA buffer supplemented with complete protease inhibitor cocktail (Roche, Basel, Switzerland). Lysates were then sonicated for $10 \mathrm{~min}$ and analysed by western blot using standard SDS-polyacrylamide gel electrophoresis (SDS-PAGE) techniques. 
In brief, protein samples were boiled in Laemmli buffer, run in $8 \%$ polyacrylamide gels and transferred onto polyvinylidene difluoride membranes. The membranes were incubated overnight at $4{ }^{\circ} \mathrm{C}$ with the appropriate primary antibodies. After washing, membranes were incubated with specific secondary horseradish peroxidase-linked antibodies (DAKO) and visualised using the enhanced chemiluminescence reagent (Biological Industries).

Image analysis. The immunohistochemistry (IHC) of intestinal sections was visualised in an Olympus BX61 microscope (Olympus, Shinjuku, Tokyo, Japan), and images were taken using the cellSens Digital Imaging software (Olympus). Measurement of tumour spheroid length (diameter) was performed automatically with ImageJ Software (National Institutes of Health, Bethesda, MD, USA, https://imagej.nih.gov/ij/, 1997-2016) analysis. Quantification of IHC for Ki67 was done using Cell Profiler (Broad Institute, Cambridge, MA, USA). Immunofluorescence images of intestinal organoids and spheroids were taken in a Leica SP5 TCS upright microscope and the Leica Application Suite Advanced Fluorescence software (Wetzlar, Germany).

RNA-Seq experiment and analysis. Total RNA from three biological replicates per condition was extracted using RNeasy Micro Kit (Qiagen, Hilden, Germany). The RNA concentration and integrity were determined using Agilent Bioanalyser (Agilent Technologies, Santa Clara, CA, USA). Libraries were prepared and sequenced at the CRG Genomics unit (Barcelona, Spain) using standard protocols on an Illumina HiSeq2500 (San Diego, CA, USA). Heatmaps were generated using R studio (https://www.rstudio.com/) and GSEA, and statistical analysis was performed with publicly available software from the Broad Institute (http:// www.broadinstitute.org/gsea/index.jsp).

\section{RESULTS AND DISCUSSION}

IKK $\alpha$ deletion in the intestinal epithelium reduces tumour formation and proliferation. The IKK/NF- $\kappa \mathrm{B}$ signalling pathway has emerged as a key regulator in multiple cancer types, including colon cancer (DiDonato et al, 2012). However, NF- $\kappa$ B also exerts multiple essential physiological functions affecting cell survival that makes its general inhibition extremely toxic (Lam et al, 2005; Gasparian et al, 2009; Wright, 2010).

As IKK $\alpha$ is not required for this general NF- $\kappa \mathrm{B}$ function, and previous studies suggested its crucial role in intestinal tumourigenesis, we now studied the specific contribution of intestinal epithelial IKK $\alpha$ to neoplastic transformation. We used a mice strain carrying Cre recombinase under the control of Villin promoter (Villin-Cre). As Villin is specifically expressed in the epithelial cells of the small and large intestine (Madison et al, 2002), crossing this strain with the one containing loxP site-flanked Ikk (Gareus et al, 2007) resulted in tissue-specific deletion of the kinase. We then crossed intestinal-specific Ikk $\alpha \mathrm{KO}$ mice with $A p c^{\mathrm{Min} /+}$ mice to induce intestinal cell transformation in an IKK $\alpha$-deficient background (Figure 1A). All different genotypes were born at the expected Mendelian ratios and showed no evident growth defects during the first 3 months of age, indicating that intestinal epithelial IKK $\alpha$ was dispensable for tissue homeostasis (data not shown). Further analysis of 3 -month-old animals carrying the $A p c^{\mathrm{Min} /+}$ allele demonstrated that IKK $\alpha$ deficiency imposed a significant decrease in the number of tumours arising in the small intestine when compared with the Ikk $\alpha$ WT littermates or mice carrying one copy of the $I k k \alpha$ gene $\left(I k k \alpha^{+/-}\right.$) (Figures $1 \mathrm{~B}$ and C). Next, we studied the possibility that reduced proliferation of transformed cells might contribute to the observed phenotype. By IHC analysis, we found that $I k k \alpha$ WT adenomas showed a significantly higher percentage of proliferating Ki67-positive cells when compared with the Ikk $\alpha$ $\mathrm{KO}$ adenomas (Figures 1D and E). In contrast, we consistently failed to detect any histological difference or changes in the number of Ki67-positive cells in the nontransformed intestinal mucosa of $I K K \alpha \mathrm{WT}$, heterozygous or KO animals (Figures $1 \mathrm{~F}$ and $\mathrm{G})$. Because active $\beta$-catenin plays a pivotal role in $A p c$-mutant tumour initiation and maintenance (Van de Wetering et al, 2002) and it was previously identified as a target of IKK $\alpha$ (Albanese et al, 2003), we aimed to determine whether nuclear $\beta$-catenin levels were reduced in the IKK $\alpha$ KO background. By IHC analysis we found that $I k k \alpha \mathrm{KO}$ tumours show a significant decrease in the levels of nuclear $\beta$-catenin as compared with the $I k k \alpha$ control counterparts (Figures $1 \mathrm{H}$ and $\mathrm{I}$ ).

We next explored the possibility that decreased tumour number in the $A p c^{\mathrm{Min} /+} I k k \alpha \mathrm{KO}$ mice were associated to increased apoptosis of the transformed cells. To do so we checked the levels of cleaved caspase 3. By IHC analysis of Ikk $\alpha$ WT and KO Apc $c^{\mathrm{Min} /}$

${ }^{+}$intestines, we observed very few cleaved caspase 3-positive areas within the tumours of both $I k k \alpha$ genotypes (Figure 1J). As a positive control, intestines of $\gamma$-irradiated mice showed consistent cleaved caspase 3 staining (Figure $1 \mathrm{~K}$ ).

These results indicate that intestinal epithelial IKK $\alpha$ is essential for tumour initiation and tumour cell proliferation, likely through regulation of $\beta$-catenin signalling, but it is dispensable for maintaining normal homeostasis and proliferation of the intestine, a situation that is clinically exploitable. Whether differences on $\beta$ catenin activation were due to direct phosphorylation by IKK $\alpha$ need to be further investigated.

IKK $\alpha^{-I-}$ tumouroids show a decrease in size and proliferation. The in vivo experiments described above provide strong evidence of the role of IKK $\alpha$ in tumour formation in the $\mathrm{APC}^{\mathrm{Min} /+}$ mouse model. To further investigate the contribution of IKK $\alpha$ requirement in a pure intestinal epithelial tumour model, we used the ex vivo $3 \mathrm{D}$ culture system, in which single primary intestinal cells with tumour-initiating capability generate spheroidal structures (Sato et al, 2009, 2011). We will here refer to these tumour

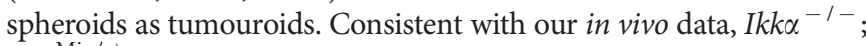
$A p c^{\mathrm{Min} /+}$ adenoma cells generated tumouroids that were significantly smaller in size than $I k k \alpha$ WT counterparts (Figure 2A). This growth-deficient phenotype was much more pronounced in the initial cultures and attenuated after serial passaging of the tumouroid cultures. The significance of this result was confirmed by a careful quantification of sphere diameter (Figure 2B). Similar to that observed in the normal intestine, 3D organoid cultures, which were derived from nontransformed intestinal epithelial stem cells, showed no differences in their growing capacity when comparing $I k k \alpha^{+/+}$and $I k k \alpha^{-/-}$genotypes (Figure $2 \mathrm{C}$ ). Immunofluorescence analysis of Ki67 expression demonstrated that $I k k \alpha^{-1-}$ tumouroids were almost depleted from proliferating cells compared with $I k k \alpha^{+1+}$ structures (Figures 2D and E). These results identify epithelial $\mathrm{IKK} \alpha$ as an important contributor to intestinal tumour initiation activity ex vivo.

IKK $\alpha$ governs tumouroid growth by regulating stem cell proliferation and cell cycle-related gene programmes. We aimed to investigate the mechanisms underlying epithelial IKK $\alpha$ function in transformed cells by defining the transcriptional programmes that depend on IKK $\alpha$ in the $A p c^{\mathrm{Min} /+}$ tumouroids. We performed RNA-seq from $A p c^{\mathrm{Min} /+} I k k \alpha$ WT or IKK $\alpha$ KO tumouroid cells. Data are accessible at the NCBI GEO database (Edgar et al, 2002), accession GSE101415. Unsupervised cluster analysis demonstrated a clear co-segregation of WT and KO RNA samples (Figure 3A). Importantly, the transcriptional profile of $I k k \alpha \mathrm{KO}$ tumouroids showed a significant decrease in the levels of a previously defined intestinal stem cell (ISC) signature (Muñoz et al, 2012) (Figure 3B), including genes essential for maintaining ISC function such as Notch1 (Riccio et al, 2008; Fre et al, 2011), Cdca7 (Guiu et al, 2014), Lgr5 (Barker et al, 2007), Ephb2 (Batlle et al, 2002; Merlos-Suárez et al, 2011), Ascl2 (van der 
Flier et al, 2009) or Lrig1 (Wong et al, 2012), among others. We further confirmed these results by qRT-PCR of several of these genes in a different set of tumouroids from both genotypes (Figure 3C). By Gene Set Enrichment Analysis (GSEA) we identified several pathways that were miss-regulated in the IKK $\alpha$ - deficient adenoma cells compared with the WT. This applies to the apoptosis pathway that was significantly enriched in the absence of IKK $\alpha$ (Figures 3D and F), involving genes such as RIPK1, TRADD, FASLG, FAS and CASP8 among others. In contrast, IKK $\alpha$-deficient adenomas showed a decrease in cell cycle-related genes

A

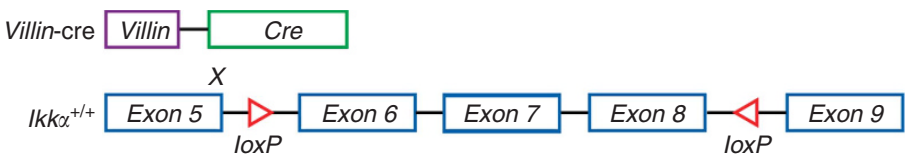

$$
\begin{aligned}
& \begin{array}{l}
\text { After Cre recombination } \\
I k k \alpha^{-1-} \text { Exon } 5 \text { Exon } 9 \\
\hline
\end{array}
\end{aligned}
$$

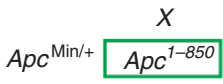

B
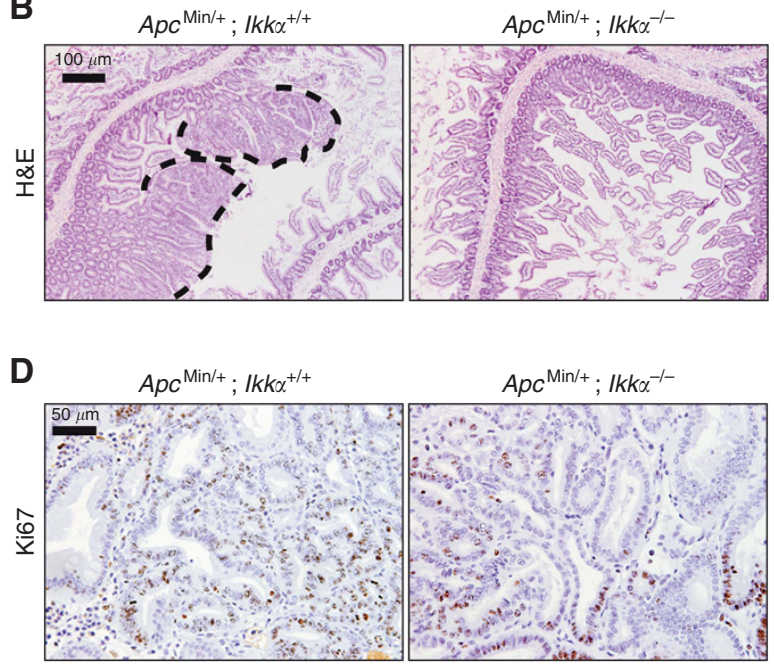

$\mathbf{F}$

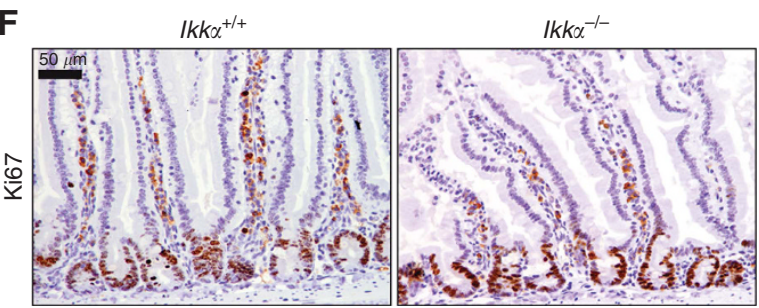

H

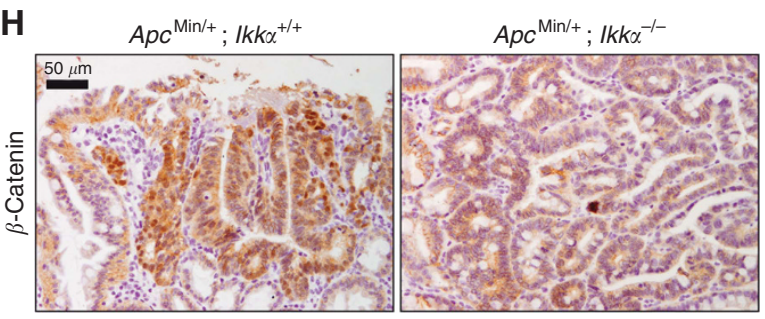

$\mathbf{J}$

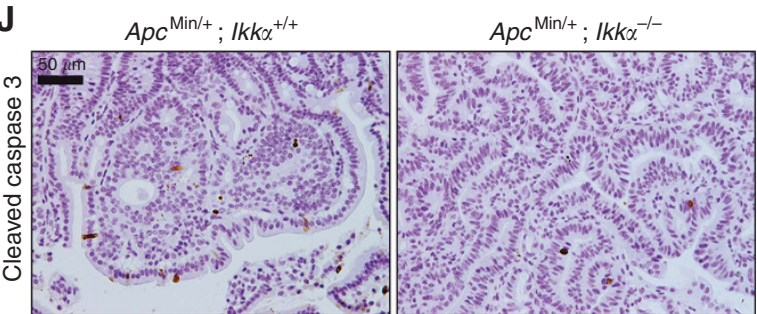

C

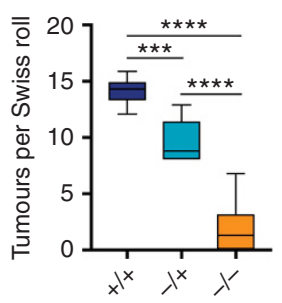

E

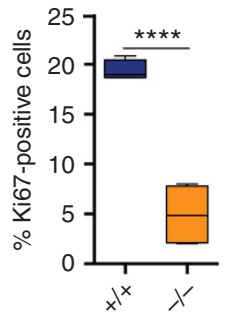

G

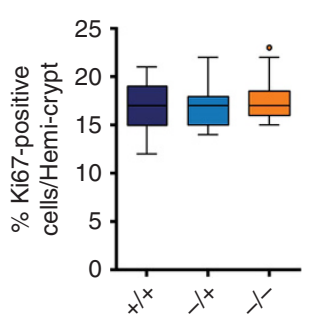

I

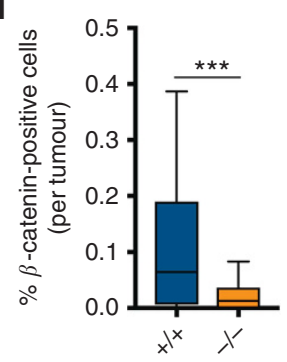

K

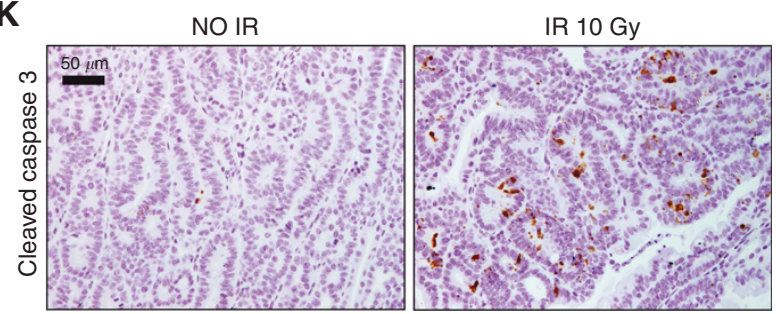


A

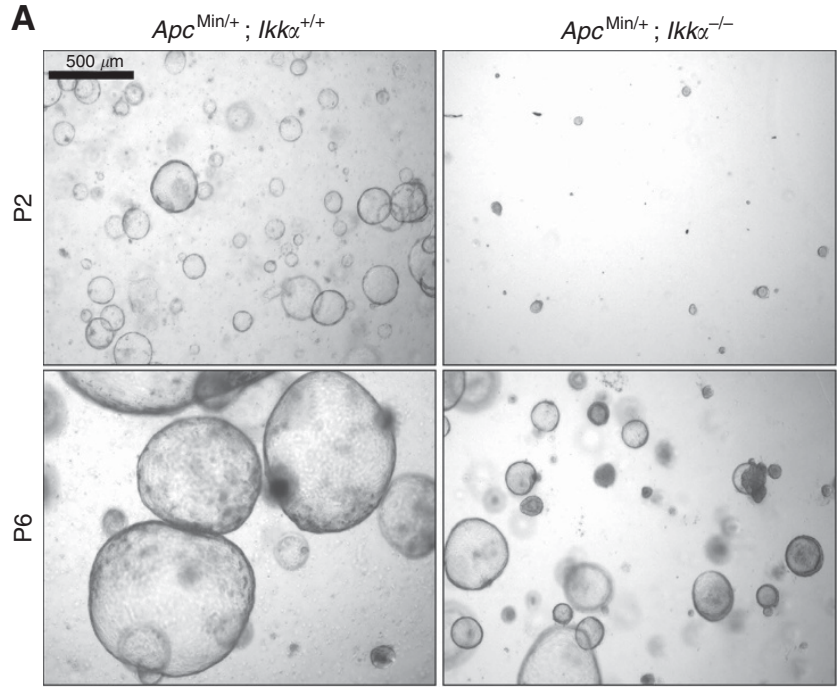

C

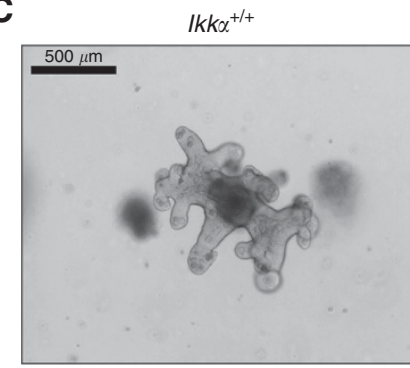

$I k k \alpha^{+/-}$

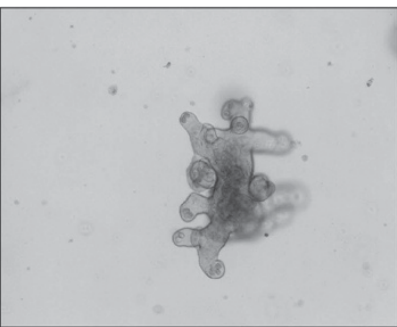

B

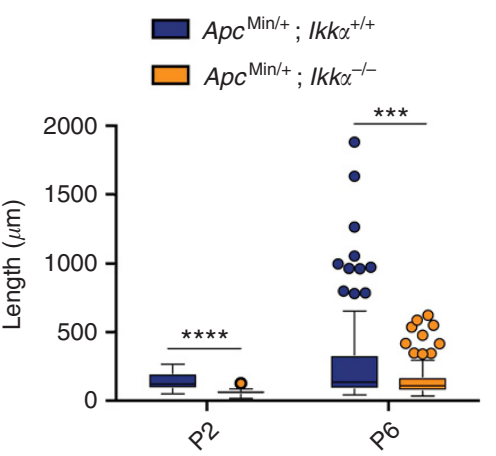

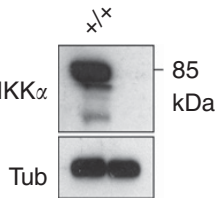

85

$I k k \alpha^{-/-}$

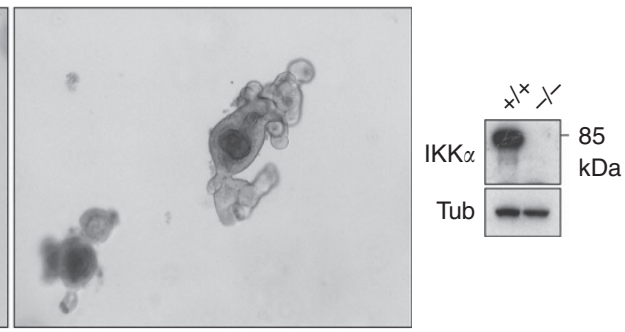

D $A p c^{\mathrm{Min} /+} ; I k \alpha^{+/+}$ $A p c^{\mathrm{Min} /+} ; \mathrm{lkk \alpha ^{-- }}$

E
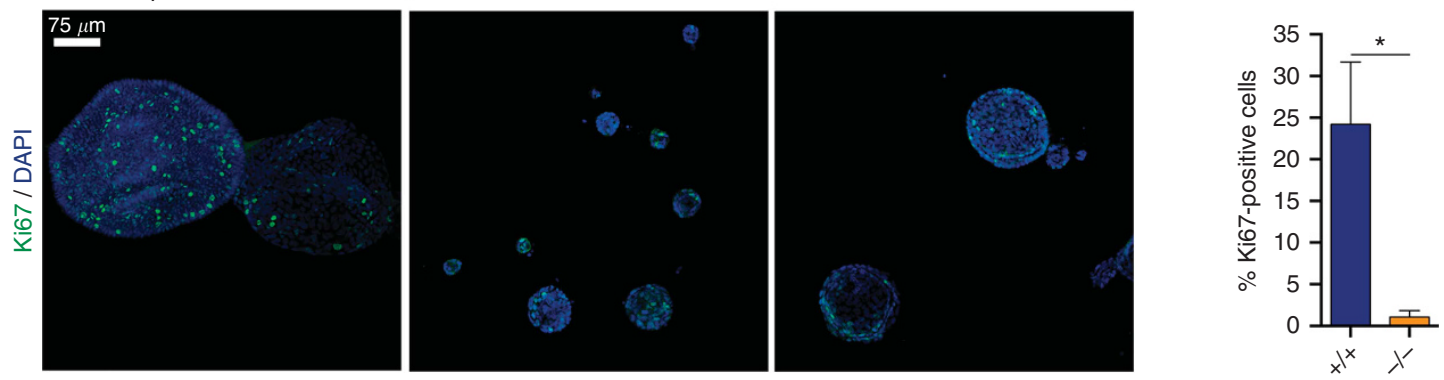

Figure 2. I $k \mathrm{k} \alpha^{-1-}$ tumouroids show a decrease in size and proliferation. (A) Representative images of growing tumouroids from the indicated genotypes. Western blot analysis of IKK $\alpha$ is shown in the right panel. P= passage. (B) Quantification of tumouroid length from three independent experiments performed. (C) Representative images of organoid cultures from nontransformed $I k k \alpha^{+/+}$and $I k k \alpha^{-/-}$intestinal stem cells and western blot analysis to demonstrate the efficiency of $I k k \alpha$ deletion. Western blot showing the levels of $I k k \alpha$ in a representative culture from the

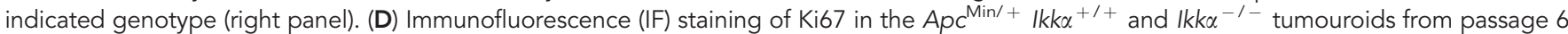
grown in Matrigel (Corning). (E) Quantification of the percentage of Ki67-positive cells from three independent experiments that was performed as in (D). The graph shows the average percentage and s.d. of the mean. Magnification of images is indicated. For statistical analysis we used ordinary one-way ANOVA or unpaired t-test. $P$-values are indicated as ${ }^{\star} P<0.05, * \star \star P<0.001$ and ${ }^{\star \star \star \star} P<0.0001$.

Figure 1. The IKK $\alpha$ deletion in the intestinal epithelium reduces adenoma formation and proliferation. (A) Schematic representation of the strategy used to generate the compound mice used in our study. (B) Representative images of H\&E staining of $A p c^{\mathrm{Min} /+} ;{ }^{\prime} k_{k \alpha}{ }^{+/+}$and $A p c^{M i n} /$ ${ }^{+} ; \mathrm{lkk \alpha ^{-/- }}$ intestinal Swiss rolls. Dashed lines delimited two different tumours present in the Apc ${ }^{\mathrm{Min} /{ }_{+}^{+}} ; \mathrm{lkk \alpha}{ }^{+/+}$image. (C) Quantification of tumour number in the $A p c^{\mathrm{Min} /+} ; I K \mathrm{K \alpha}^{+/+}$and $\mathrm{APC} \mathrm{Min} /+; I K K \alpha^{-/-}$intestinal Swiss rolls. (D) Representative images of Ki67 immunohistochemistry (IHC) in $\mathrm{Apc}^{\mathrm{Min} /+} ; \mathrm{lkk \alpha ^{+/+ }}$ and $l \mathrm{kk \alpha}^{-/-}$adenomas. (E) Quantification of Ki67-positive cells shown in (D). (F) Immunohistochemistry of Ki67 in Ikk $\alpha^{+/+}$and $1 k_{k \alpha} \alpha^{-1-}$ intestines and (G) quantification of the number of Ki67-positive cells per hemi-crypt. Graphs represent the average number of tumours (C) or percentage of cells ( $\mathbf{E}$ and $\mathbf{G}$ ) per Swiss roll from animals of each genotype. ( $\mathbf{H}$ and $\mathbf{I})$ The IHC analysis of $\beta$-catenin $(\mathbf{H})$ and quantification of percentage of tumour cells of each genotype showing nuclear $\beta$-catenin staining (I). ( $\mathbf{J}$ and $\mathbf{K}$ ) The IHC of cleaved caspase 3 in tumours of the indicated genotypes $(\mathbf{J})$ or obtained from mice irradiated $3 \mathrm{~h}$ before processing the samples $(\mathbf{K})$. Representative images for $(\mathbf{H}, \mathbf{J}$ and $\mathbf{K})$ are shown. For statistical analysis, ordinary one-way ANOVA or unpaired t-test was used and the $P$-values are indicated as ${ }^{\star \star \star} P<0.001$ and $* \star \star \star P<0.0001$. 
A

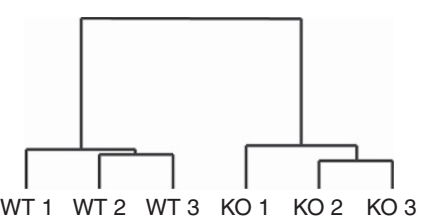

B

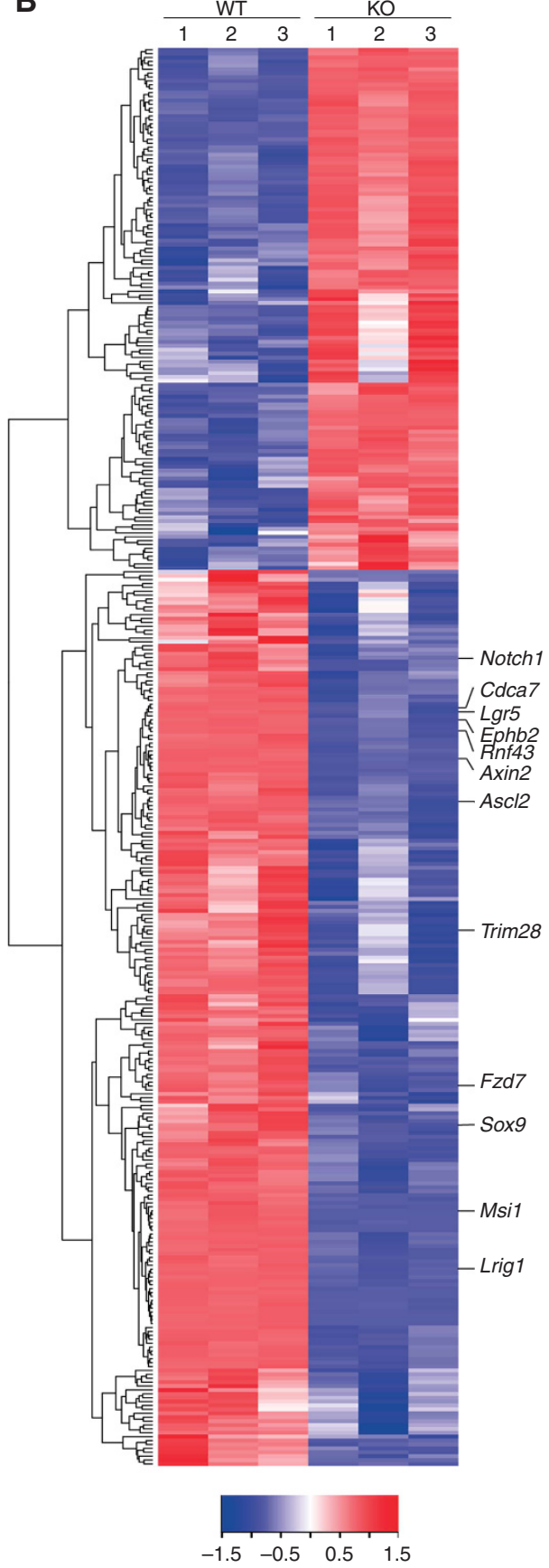

C

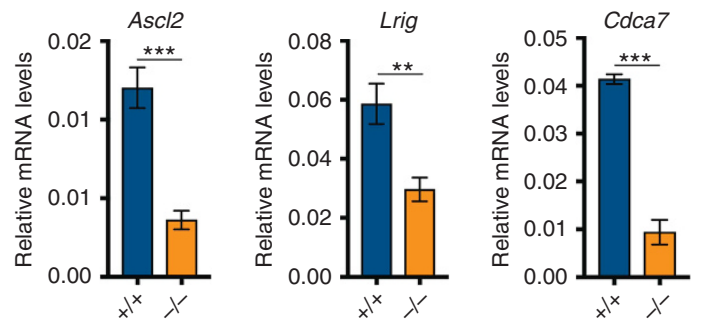

D

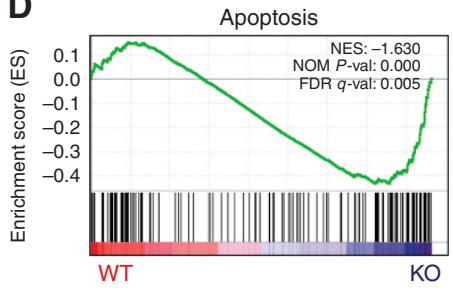

E
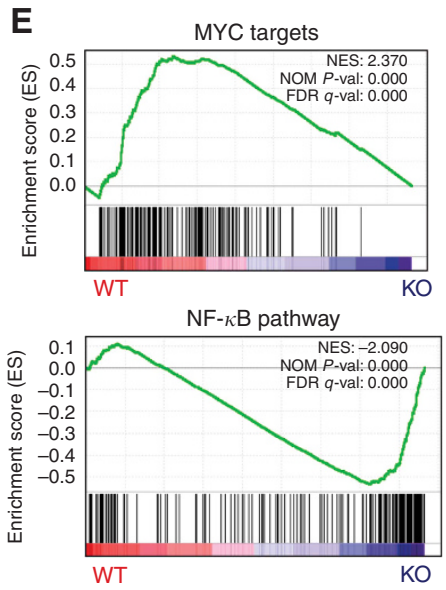

$\mathbf{F}$

\begin{tabular}{|l|l|l|l|}
\hline \multicolumn{4}{|c|}{ Enriched in WT } \\
\hline Gene sets & NES & \multicolumn{3}{l|}{$P$-value } & \multicolumn{1}{l|}{ FDR q-value } \\
\hline E2F targets & 2.69 & 0.000 & 0.000 \\
\hline Oxidative phosphorylation & 2.67 & 0.000 & 0.000 \\
\hline MYC targets V1 & 2.37 & 0.000 & 0.000 \\
\hline G2M checkpoint & 2.21 & 0.000 & 0.000 \\
\hline MYC tagets V2 & 1.88 & 0.000 & 0.000 \\
\hline Interferon alpha response & 1.63 & 0.000 & 0.008 \\
\hline Fatty acid metabolism & 1.52 & 0.000 & 0.016 \\
\hline Interferon gamma response & 0.004 & 0.004 & 0.020 \\
\hline \multicolumn{4}{|l|}{ Enriched in KO } \\
\hline Gene sets & NES & $P$-value & FDR q-value \\
\hline p53 pathway & -2.11 & 0.000 & 0.000 \\
\hline EMT & -2.11 & 0.000 & 0.000 \\
\hline TNF $\alpha$ signalling via NF- $\kappa$ B & -2.09 & 0.000 & 0.000 \\
\hline TGF $\beta$ signalling & -2.02 & 0.000 & 0.000 \\
\hline Coagulation & -1.86 & 0.000 & 0.001 \\
\hline Apical junction & -1.71 & 0.000 & 0.004 \\
\hline Inflammatory response & -1.71 & 0.000 & 0.004 \\
\hline KRAS signalling UP & -1.70 & 0.000 & 0.004 \\
\hline Oestrogen & -1.69 & 0.000 & 0.003 \\
\hline Oestrogen response late & -1.68 & 0.000 & 0.003 \\
\hline UV response DN & -1.65 & 0.000 & 0.006 \\
\hline Complement & -1.64 & 0.001 & 0.006 \\
\hline Apoptosis & -1.63 & 0.000 & 0.005 \\
\hline Hypoxia & -1.57 & 0.000 & 0.010 \\
\hline Cholesterol homeostasis & -1.57 & 0.006 & 0.010 \\
\hline
\end{tabular}

Figure 3. $l k k^{-1-}$ tumouroids show altered regulation of intestinal stem cell genes. (A) Unsupervised hierarchical clustering analysis based on Euclidean distances of logged normalised counts between samples from three independent samples per genotype analysed. (B) The RNA-seq heatmap showing differential expression of genes involved in intestinal stemness with scaled (z-score) columns. (C) The q-PCR analysis of the indicated genes in $l k k \alpha^{+/+}$(WT) and $l k \alpha^{-1-}(K O)$ tumouroids. The graphs represent the average value and s.d. from two independent tumouroids of each genotype analysed in triplicate. (D) The GSEA plots of genes differentially expressed in Ikk WT and KO from the apoptosis and cell cycle checkpoint-related gene sets. (E) The GSEA plots of differentially expressed genes from MYC- and NF- $\kappa$ B-related gene sets. The pathways shown were particularly selected from significantly enriched ones to better explain the phenotypes observed. (F) Table showing all

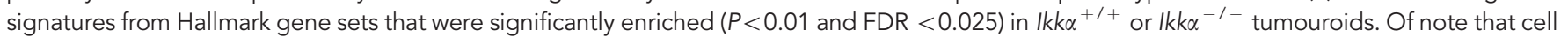
cycle checkpoint-related gene set was identified from Reactome gene sets. $P$-value and false discovery rate (FDR) are shown. For statistical analysis we used ordinary one-way ANOVA or unpaired t-test. $\mathrm{DN}=$ down; $\mathrm{KO}=$ knock out; $\mathrm{NES}=$ normalised enrichment score; $\mathrm{WT}=$ wild-type. $\mathrm{P}$-values are indicated as ${ }^{*} P<0.01$ and ${ }^{\star \star \star} P<0.001$. 
(Figure 3D). IKK $\alpha$ deficiency also led to a decrease in the protumourigenic MYC signature, whereas it did not correlate with a general reduction in the canonical NF- $\kappa \mathrm{B}$ signature (Figures $3 \mathrm{E}$ and $F$ ), further suggesting that $I K K \alpha$ function in the intestinal adenoma stem cells is mainly NF- $\kappa \mathrm{B}$ independent. These results are in agreement with our previous data indicating that IKK $\alpha$ regulates cell survival and proliferation in human CRC cells (Fernández-Majada et al, 2007a; Margalef et al, 2012, 2015).

Collectively, our results demonstrate that intestinal epithelial IKK $\alpha$ exerts a cell-autonomous function in the intestinal adenoma stem cells affecting proliferation and stemness. Importantly, our data support the concept that IKK $\alpha$ is a plausible target for the development of new anticancer therapies from which CRC patients could benefit. Further investigation on the upstream and downstream effectors of cancer-associated IKK $\alpha$ activity will provide valuable information for the design of better and more selective therapies against human CRC. In fact, identification of the apoptotic pathway as a target of IKK $\alpha$ supports the notion that its inhibition could sensitise tumour cells to compounds that induce cell death such as chemotherapeutic agents.

\section{ACKNOWLEDGEMENTS}

We thank Manolis Pasparakis for providing the IKK $\alpha^{\text {lox }}$ mice, Sarah Bonnin from the CRG Genomics Unit for expert help and advice regarding sequencing and data analysis and Kitty van Zwieten for technical support. This work was supported by Fondo de Investigación Sanitaria, ISCIII (Grants PI16/00437 and PIE15/ 00008), Fundació la Marató de TV3 (Grant 20131210) and Agència de Gestió Ajuts Universitaris de Recerca (SGR 9015-356014/2017).

\section{CONFLICT OF INTEREST}

The authors declare no conflict of interest.

\section{AUTHOR CONTRIBUTIONS}

$\mathrm{CC}$ and PM performed the experiments and wrote the manuscript. $\mathrm{JG}$ and $\mathrm{AV}$ performed experiments. $\mathrm{AB}$ and $\mathrm{LE}$ designed the experiments and wrote the manuscript.

\section{REFERENCES}

Albanese C, Wu K, D’Amico M, Jarrett C, Joyce D, Hughes J, Hulit J, Sakamaki T, Fu M, Ben-Ze'ev A, Bromberg JF, Lamberti C, Verma U, Gaynor RB, Byers SW, Pestell RG (2003) IKKalpha regulates mitogenic signaling through transcriptional induction of cyclin D1 via Tcf. Mol Biol Cell 14(2): 585-5899.

Barker N, van Es JH, Kuipers J, Kujala P, van den Born M, Cozijnsen M, Haegebarth A, Korving J, Begthel H, Peters PJ, Clevers H (2007) Identification of stem cells in small intestine and colon by marker gene Lgr5. Nature 449(7165): 1003-1007.

Batlle E, Henderson JT, Beghtel H, van den Born MM, Sancho E, Huls G, Meeldijk J, Robertson J, van de Wetering M, Pawson T, Clevers H (2002) Beta-catenin and TCF mediate cell positioning in the intestinal epithelium by controlling the expression of EphB/ephrinB. Cell 111(2): 251-263.

Cheung AF, Carter AM, Kostova KK, Woodruff JF, Crowley D, Bronson RT, Haigis KM, Jacks T (2010) Complete deletion of Apc results in severe polyposis in mice. Oncogene 29(12): 1857-1864.

DiDonato JA, Mercurio F, Karin M (2012) NF-אB and the link between inflammation and cancer. Immunol Rev 246(1): 379-400.
Dow LE, O’Rourke KP, Simon J, Tschaharganeh DF, van Es JH, Clevers H, Lowe SW (2015) Apc restoration promotes cellular differentiation and reestablishes crypt homeostasis in colorectal cancer. Cell 161(7): $1539-1552$.

Drost J, van Jaarsveld RH, Ponsioen B, Zimberlin C, van Boxtel R, Buijs A, Sachs N, Overmeer RM, Offerhaus GJ, Begthel H, Korving J, van de Wetering M, Schwank G, Logtenberg M, Cuppen E, Snippert HJ, Medema JP, Kops GJ, Clevers H (2015) Sequential cancer mutations in cultured human intestinal stem cells. Nature 521(7550): 43-47.

Edgar R, Domrachev M, Lash AE (2002) Gene Expression Omnibus: NCBI gene expression and hybridization array data repository. Nucleic Acids Res 30(1): 207-210.

Fearon ER (2011) Molecular genetics of colorectal cancer. Annu Rev Pathol 6: 479-507.

Fearon ER, Vogelstein B (1990) A genetic model for colorectal tumorigenesis. Cell 61(5): 759-767.

Fernández-Majada V, Aguilera C, Villanueva A, Vilardell F, Robert-Moreno A, Aytés A, Real FX, Capella G, Mayo MW, Espinosa L, Bigas A (2007a) Nuclear IKK activity leads to dysregulated notch-dependent gene expression in colorectal cancer. Proc Natl Acad Sci USA 104(1): 276-281.

Fernández-Majada V, Pujadas J, Vilardell F, Capella G, Mayo MW, Bigas A, Espinosa L (2007b) Aberrant cytoplasmic localization of N-CoR in colorectal tumors. Cell Cycle 6(14): 1748-1752.

Fre S, Hannezo E, Sale S, Huyghe M, Lafkas D, Kissel H, Louvi A, Greve J, Louvard D, Artavanis-Tsakonas S (2011) Notch lineages and activity in intestinal stem cells determined by a new set of knock-in mice. PLoS One 6(10): e25785.

Gareus R, Huth M, Breiden B, Nenci A, Rösch N, Haase I, Bloch W, Sandhoff K, Pasparakis M (2007) Normal epidermal differentiation but impaired skin-barrier formation upon keratinocyte-restricted IKK1 ablation. Nat Cell Biol 9(4): 461-469.

Gasparian AV, Guryanova OA, Chebotaev DV, Shishkin AA, Yemelyanov AY, Budunova IV (2009) Targeting transcription factor NFkappaB: comparative analysis of proteasome and IKK inhibitors. Cell Cycle 8(10): 1559-1566.

Ghosh S, Karin M (2002) Missing pieces in the NF-kappaB puzzle. Cell 109(Suppl): S81-S96.

Göktuna SI, Canli O, Bollrath J, Fingerle AA, Horst D, Diamanti MA, Pallangyo C, Bennecke M, Nebelsiek T, Mankan AK, Lang R, Artis D, Hu Y, Patzelt T, Ruland J, Kirchner T, Taketo MM, Chariot A, Arkan MC, Greten FR (2014) IKK $\alpha$ promotes intestinal tumorigenesis by limiting recruitment of M1-like polarized myeloid cells. Cell Rep 7(6): 1914-1925.

Guiu J, Bergen DJ, De Pater E, Islam AB, Ayllón V, Gama-Norton L, Ruiz-Herguido C, González J, López-Bigas N, Menendez P, Dzierzak E, Espinosa L, Bigas A (2014) Identification of Cdca7 as a novel Notch transcriptional target involved in hematopoietic stem cell emergence. J Exp Med 211(12): 2411-2423.

Hayden MS, Ghosh S (2004) Signaling to NF-kappaB. Genes Dev 18(18): 2195-2224.

Hayden MS, West AP, Ghosh S (2006) NF-kappaB and the immune response. Oncogene 25(51): 6758-6780.

Jemal A, Bray F, Center MM, Ferlay J, Ward E, Forman D (2011) Global cancer statistics. CA Cancer J Clin 61(2): 69-90.

Karin M, Greten FR (2005) NF-kappaB: linking inflammation and immunity to cancer development and progression. Nat Rev Immunol 5(10): 749-759.

Lam LT, Davis RE, Pierce J, Hepperle M, Xu Y, Hottelet M, Nong Y, Wen D, Adams J, Dang L, Staudt LM (2005) Small molecule inhibitors of IkappaB kinase are selectively toxic for subgroups of diffuse large B-cell lymphoma defined by gene expression profiling. Clin Cancer Res 11(1): 28-40.

Luo JL, Tan W, Ricono JM, Korchynskyi O, Zhang M, Gonias SL, Cheresh DA, Karin M (2007) Nuclear cytokine-activated IKKalpha controls prostate cancer metastasis by repressing Maspin. Nature 446(7136): 690-694.

Madison BB, Dunbar L, Qiao XT, Braunstein K, Braunstein E, Gumucio DL (2002) Cis elements of the villin gene control expression in restricted domains of the vertical (crypt) and horizontal (duodenum, cecum) axes of the intestine. J Biol Chem 277(36): 33275-33283.

Margalef P, Colomer C, Villanueva A, Montagut C, Iglesias M, Bellosillo B, Salazar R, Martínez-Iniesta M, Bigas A, Espinosa L (2015) BRAF-induced tumorigenesis is IKK $\alpha$-dependent but NF-кB-independent. Sci Signal 8(373): ra38. 
Margalef P, Fernández-Majada V, Villanueva A, Garcia-Carbonell R, Iglesias M, López L, Martínez-Iniesta M, Villà-Freixa J, Mulero MC, Andreu M, Torres F, Mayo MW, Bigas A, Espinosa L (2012) A truncated form of IKK $\alpha$ is responsible for specific nuclear IKK activity in colorectal cancer. Cell Rep 2(4): 840-854.

Merlos-Suárez A, Barriga FM, Jung P, Iglesias M, Céspedes MV, Rossell D, Sevillano M, Hernando-Momblona X, da Silva-Diz V, Muñoz P, Clevers H, Sancho E, Mangues R, Batlle E (2011) The intestinal stem cell signature identifies colorectal cancer stem cells and predicts disease relapse. Cell Stem Cell 8(5): 511-524.

Mulero MC, Ferres-Marco D, Islam A, Margalef P, Pecoraro M, Toll A, Drechsel N, Charneco C, Davis S, Bellora N, Gallardo F, López-Arribillaga E, Asensio-Juan E, Rodilla V, González J, Iglesias M, Shih V, Mar Albà M, Di Croce L, Hoffmann A, Miyamoto S, Villà-Freixa J, López-Bigas N, Keyes WM, Domínguez M, Bigas A, Espinosa L (2013) Chromatin-bound $\mathrm{I} \kappa \mathrm{B} \alpha$ regulates a subset of polycomb target genes in differentiation and cancer. Cancer Cell 24(2): 151-166.

Muñoz J, Stange DE, Schepers AG, van de Wetering M, Koo BK, Itzkovitz S, Volckmann R, Kung KS, Koster J, Radulescu S, Myant K, Versteeg R, Sansom OJ, van Es JH, Barker N, van Oudenaarden A, Mohammed S, Heck AJ, Clevers H (2012) The Lgr5 intestinal stem cell signature: robust expression of proposed quiescent ' + 4' cell markers. EMBO J 31(14): 3079-3091.

Riccio O, van Gijn ME, Bezdek AC, Pellegrinet L, van Es JH, Zimber-Strobl U, Strobl LJ, Honjo T, Clevers H, Radtke F (2008) Loss of intestinal crypt progenitor cells owing to inactivation of both Notch1 and Notch2 is accompanied by derepression of CDK inhibitors p27Kip1 and p57Kip2. EMBO Rep 9(4): 377-383.

Sato T, Stange DE, Ferrante M, Vries RG, Van Es JH, Van den Brink S, Van Houdt WJ, Pronk A, Van Gorp J, Siersema PD, Clevers H (2011) Long-term expansion of epithelial organoids from human colon, adenoma, adenocarcinoma, and Barrett's epithelium. Gastroenterology 141(5): 1762-1772.

Sato T, Vries RG, Snippert HJ, van de Wetering M, Barker N, Stange DE, van Es JH, Abo A, Kujala P, Peters PJ, Clevers H (2009) Single Lgr5 stem cells build crypt-villus structures in vitro without a mesenchymal niche. Nature 459(7244): 262-265.
Schulze-Luehrmann J, Ghosh S (2006) Antigen-receptor signaling to nuclear factor kappa B. Immunity 25(5): 701-715.

Su LK, Kinzler KW, Vogelstein B, Preisinger AC, Moser AR, Luongo C, Gould KA, Dove WF (1992) Multiple intestinal neoplasia caused by a mutation in the murine homolog of the APC gene. Science 256(5057): 668-670.

Toll A, Margalef P, Masferrer E, Ferrándiz-Pulido C, Gimeno J, Pujol RM, Bigas A, Espinosa L (2015) Active nuclear IKK correlates with metastatic risk in cutaneous squamous cell carcinoma. Arch Dermatol Res 307(8): 721-729.

Vallabhapurapu S, Karin M (2009) Regulation and function of NF-kappaB transcription factors in the immune system. Annu Rev Immunol 27: 693-733.

van de Wetering M, Sancho E, Verweij C, de Lau W, Oving I, Hurlstone A, van der Horn K, Batlle E, Coudreuse D, Haramis AP, Tjon-Pon-Fong M, Moerer P, van den Born M, Soete G, Pals S, Eilers M, Medema R, Clevers H (2002) The beta-catenin/TCF-4 complex imposes a crypt progenitor phenotype on colorectal cancer cells. Cell 111(2): 241-250.

van der Flier LG, van Gijn ME, Hatzis P, Kujala P, Haegebarth A, Stange DE, Begthel H, van den Born M, Guryev V, Oving I, van Es JH, Barker N, Peters PJ, van de Wetering M, Clevers H (2009) Transcription factor achaete scute-like 2 controls intestinal stem cell fate. Cell 136(5): 903-912.

Wong VW, Stange DE, Page ME, Buczacki S, Wabik A, Itami S, van de Wetering M, Poulsom R, Wright NA, Trotter MW, Watt FM, Winton DJ, Clevers H, Jensen KB (2012) Lrig1 controls intestinal stem-cell homeostasis by negative regulation of ErbB signalling. Nat Cell Biol 14(4): 401-408.

Wright JJ (2010) Combination therapy of bortezomib with novel targeted agents: an emerging treatment strategy. Clin Cancer Res 16(16): 4094-4104.

This work is published under the standard license to publish agreement. After 12 months the work will become freely available and the license terms will switch to a Creative Commons AttributionNonCommercial-Share Alike 4.0 Unported License. 